\title{
On the Art and Practice of Urban Design
}

\author{
John Decker \\ Architect, urban designer and film maker living in Colorado. \\ He has taught and done design and visualization research at the University \\ of Cincinnati, Carnegie Mellon University and the University of Colorado.
}

\begin{abstract}
John Decker has been studying the form of the contemporary city and the application of cutting-edge digital representation techniques, including film making, in the urban design and planning processes for many years. In this provocative article he challenges us with the need of a comprehensive urban design theory, and discusses some of its fundamental analytical layers: mass, movement, scale, geometry, and functional units.
\end{abstract}

$T^{\text {the }}$ he last century saw humankind make remarkable industrial and technological progress. One of the outcomes of that progress is that the worldwide human population has been artificially sustained and has grown to unprecedented levels. Because of the scale of our exploding population, just about everything we do is magnified to have global implications. Around 2006 we passed a benchmark where more than half of humanity now lives in cities. We have become an urban species.

As the largest visible evidence of human presence and activity, cities have always been problematic things for their builders. They are physical constructions that must be managed; they have massive infrastructures that must be maintained; and their sheer accumulations of humanity can make them places of conflict, with many and various inequities. The things we do to build and run cities are mostly intentional, but they can have both intended and unintended outcomes. Regardless, maintaining and running a city of any size requires a very large amount of cooperative behavior and continuously tests every level of human organization.

In current history, cities are getting much larger, expanding at an unprecedented rate, and this leads to a simple fact: the larger the city, the greater the magnitude of its impacts, both positive and negative (Figure 1).

As their population increases, these cities have greater potential to create whole-world impacts. City-building is a consolidated piece of the whole of our technological capability, and as such, it creates challenges for collective humanity similar to what other consolidated pieces of technology, such as the Internet and other media, have created. Just the same, in theory everything about and in the city could be comprehensively

Note: The author is currently researching, diagramming and filming large-compound multi-urban systems, such as the Los Angeles region, that he terms hyper-cities. Some of his animated urban analysis studies can be seen on Youtube at: http://www.youtube.com/ watch?v=vgB56CIKADI designed, engineered, optimized, and brought close to selfmanagement.

\section{The Challenge}

The single biggest challenge of this time is the impact on human-built structures, including whole cities, that is potentially delivered by climate change. Cities tend to be fixed installations and as such they have limited capability to absorb unprecedented environmental loads; many may not be able to survive them in any form at all. Every city is potentially vulnerable, but coastal areas are the most so, and a high percentage of large cities are sited in coastal areas. Here climate change impacts, such as larger storms and coastal erosion, could have the most severe impacts. Ultimately, sea and tide levels will rise and significant areas of coastal territory may be inundated or broken and eroded away, which will be devastating to ports and other seaside urban structures.

Cities will need to be significantly retrofitted or outright reconstructed so that they can survive the shocks of climate change and remain intact and operational. Whole sections of a city may require relocation as land is either lost or needs to be radically repurposed. Neglecting the level of human organization that will be required to be capable of executing these things, a massive amount of fully comprehensive, fully multidisciplinary and multi-scalar urban design will first need to be developed. In order to design at these scales, the physical entity of the city must be fully understood. Its structures and systems must be mapped and engineered, based on science and analysis.

In short, there needs to be a unified method or process for urban design that is built on a comprehensive urban design theory. This theory must be clearly considered and logically describable, presenting a method that is repeatable and that will yield consistent and measurable results. So as an attempt at devising this method, I discuss my approach in this paper. 


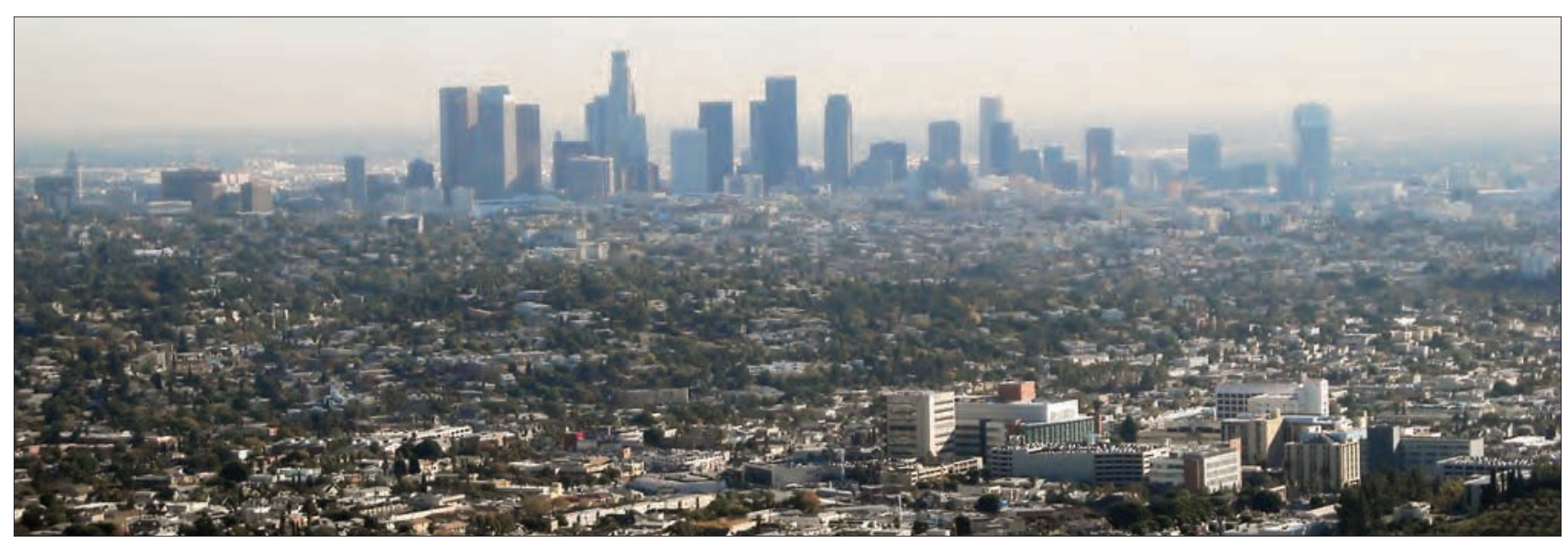

Figure 1: The complexity of a large modern world-city is well represented by Los Angeles, in this view from Griffith Park. (source: Wikipedia/Creative Commons)

\section{Patterns of Settlement}

Cities occur where they do for a whole set of convergent human reasons. They are formed at the crossroads between physical human needs, art, and commerce. People build cities as a natural outgrowth of their human tendencies; humans began seeking and building shelters at a very early stage in their development. Being gregarious, they built their shelters in groups. This passed through phases of larger and larger groups until eventually it evolved into cities and attendant civilization. Cities can therefore be considered natural formations, and when multiple cities are observed externally, such as from space, they tend to be composed of recognizable patterns and structures, and show much commonality. These patterns will remain similar, regardless of differences among cities in their organization, culture, economy, zoning patterns, or system of governance.

If one looks at the overall shapes of just the built-up areas in a group of cities, one can deduce a great deal of information about each city and its relationship to the cities around it. The forms and articulation of these shapes have meaning which can be identified, isolated, and read. Spatial and organizational codes can be revealed, and these codes can serve to guide design for subsequent intervention (Figure 2)

In the pattern of boundaries and properties on the land in a single city, one can see what has been termed pulverization, or the visual grain of the divisions in the continuous land created by the economic need to obtain maximum yield out of any piece of improved land. (Harvey, 1985) The scale and component shapes of this grain reveal a great deal about the nature and history of a given city.

Looking at other patterns and structures, one can see convergence, or describable similarity between the forms of the same type of components, when one city is compared to another. One can quickly recognize their purpose and know a great deal about their function, because most people will have had personal, direct experience with something similar in their own city and country.

Looking at much larger groups of cities, such as images of large areas at night, relationships and connections between the cities can be observed, and patterns of growth or interconnections become apparent.

\section{Complexity}

The city is a complex manifold of structures and related actions. To analyze it, one must take it apart and study its systems and components in graphical reduction and isolation. A city is a physical entity. It exists in physical space and is subject to the laws of nature. The physical city can be better understood by using analogy to other physical phenomena.

Urban structures are first environmental entities arrayed on the land and subject to all surrounding environmental dynamics, including the shortcomings of the thermodynamic principle. City installations don't simply interrupt environmental flow, they often actively interact with it; and they induce perturbations that are persistent and are felt some distance downstream. Urban components are designed with the primary intention that have the capability, and the arrrangement, to resist environmental pressures. They must shed water, resist gravity, remain thermally comfortable, and sustain various other loads. Engineering and design should be applied to both new and existing city structures to minimize the environmental disruptions they can create.

The city is also an organic entity. It is subject to growth, development, and other changes; it replicates and duplicates itself at multiple scales and frequencies as its needs expand. Like other organic structures, its parts are ideally highly interconnected. These arrays of interconnection must be capable of being intensified and rearranged as needed, with the least possible disruption to the functioning whole of the organism. 


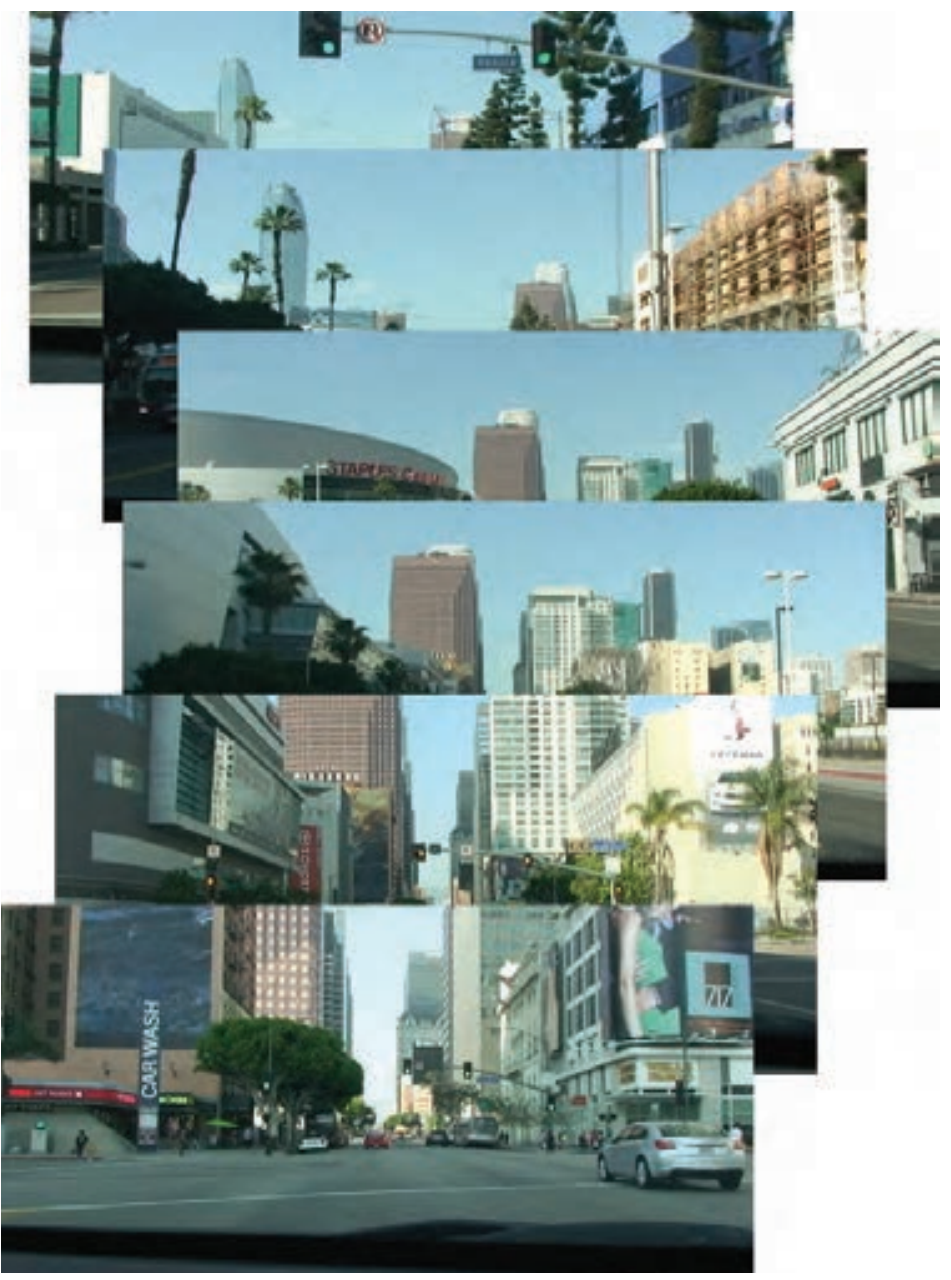

Figure 3: Frames from a movie that form a serial-view of moving in LA. North on Figueroa, just south of downtown.

build-out but also all of its more far-flung influences. All cities sit in networks of fixed supply lines and territorial trade routes. Large modern cities often draw power, water, fuel, and other resources from great distances. If considered in this way, modern urbanization and the largest parts of its extended infrastructure will be seen as interconnected, and in some cases, continuous over hundreds of miles and through multiple regions. Design must consequently be applied from a much larger perspective and must account for these real impacts extended well outside of a given city. Ultimately a form of overall urban design must be applied to the entire regional infrastructure associated with these systems of cities or mega-urbanizations.

It is possible that with significant advancement in our capability to build cities and our increased global systems of cooperation, the integration of the extended urbanization could eventually reach the point of totality, becoming an almost singular, planet-wide hyper-city.

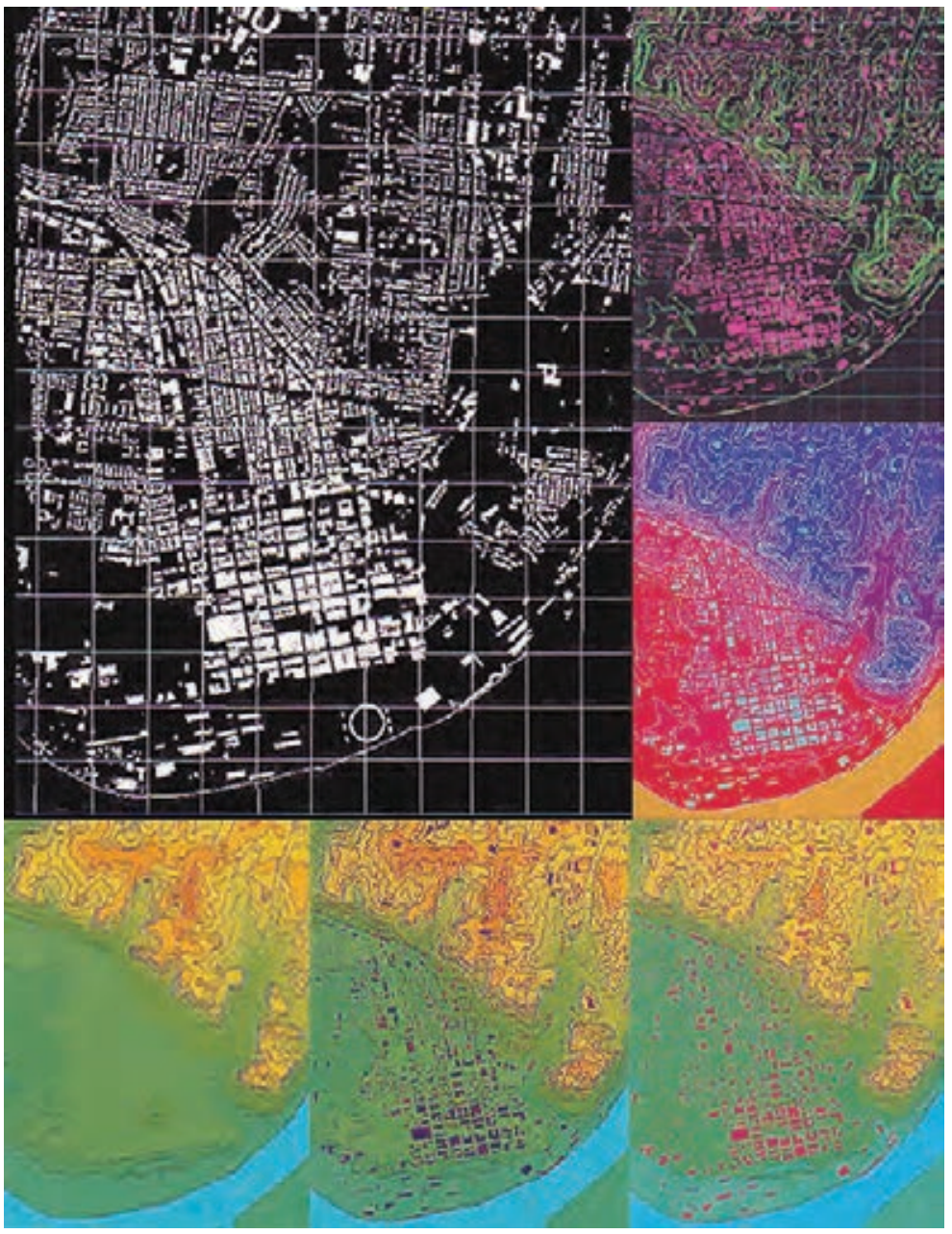

Figure 4: The figure-ground of central Cincinnati plus five smaller views that show several ways of looking at the relationship with the underlying land.

\section{Functional Units}

Since many urban studies and planning initiatives are sharply limited to a boundary defined by political, demographic, or economic intention, other important factors and actions can be left out of the study area, or completely neglected, even if part is inside the boundary. One consequence of this can be that the best solution lies outside of the study area and will thus be left unconsidered. A better approach is to identify and then break the city into its set of functional units.

A functional unit is a portion of the city that includes all of the buildings, movement systems, and natural systems within its area that are necessary to represent at least one complete urban function or action (Figure 5). To fully study a functional unit, the defined unit must include areas that follow and extend out along movement corridors, ideally to where they meet the next set of functional units. Proposed urban design studies of a district or facility should first define the main inclusion 
in the study and then include in the boundary more of the movement and infrastructural connections, environmental flows, and downstream impact areas. A basic functional urban component will have a core, or center, attached to rays, which include a combination of the movement system and the associated linear building developments along it. As one looks at larger areas, the city is seen to have multiple cores, with multiple rays extending between the cores, and at larger scales the many cores are seen to have a hierarchy of sizes and levels of integration by numerous rays to all of the others (Figure 6).

This descriptive system is both a derivation from and integration of Lynch's paths and nodes system. It differs in that by using graphics of direct physical data, this system can show concentrations of development associated with portions of the movement and environmental system. Bounding these studies appropriately around at least one complete functional unit will improve the success of every type of urban initiative it is applied to, at every order of urban scale (Lynch 1960).

Figure 5: The functional unit of Cincinnati used for a study of approaches and entry points to the downtown (top). The functional fabric in the central core of Pittsburgh (bottom).
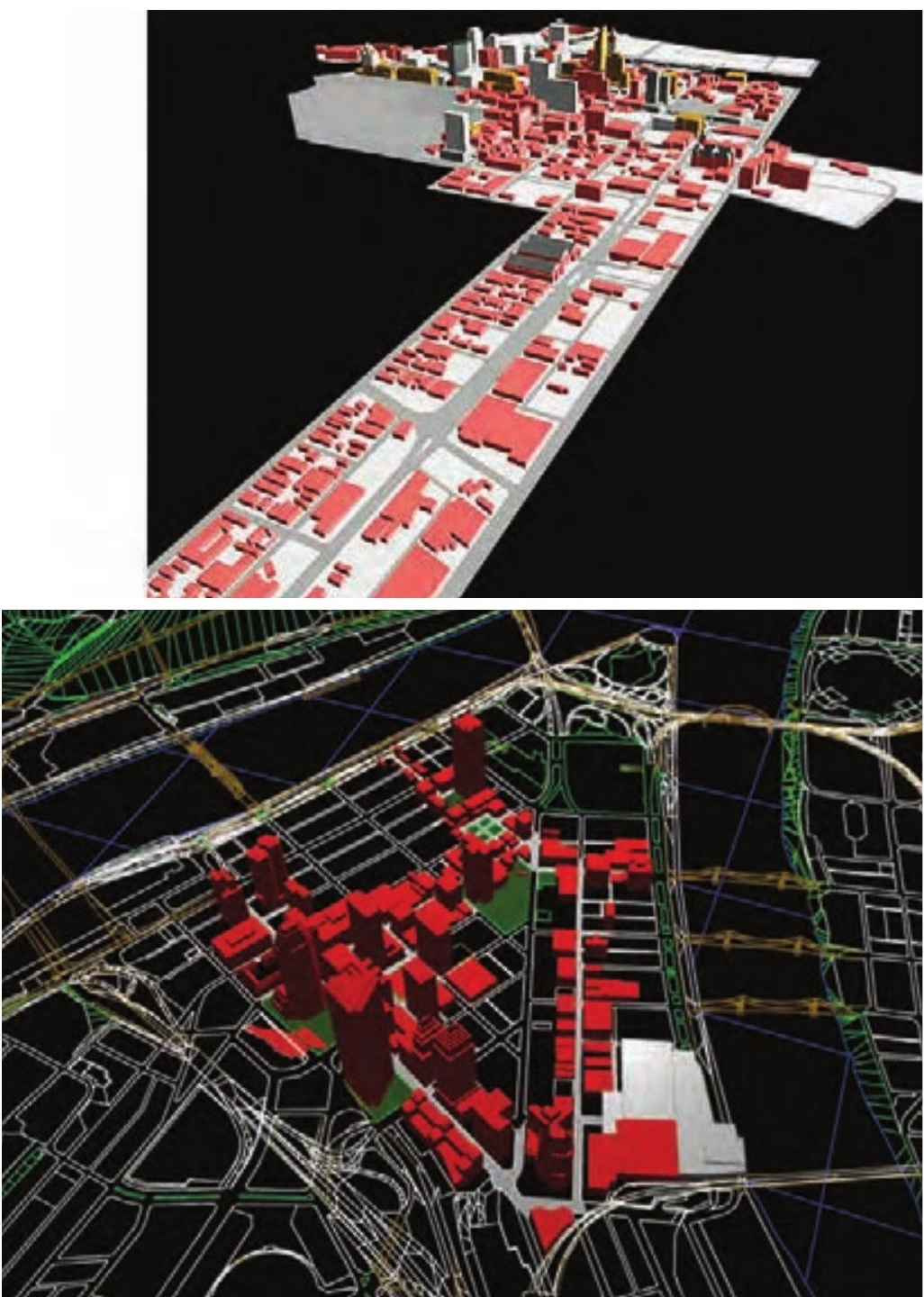

\section{Geometric Realms}

As previously stated, as physical things, cities are spatial entities and geometry is the best way to describe and understand their spatial structure. Every physical pattern, action, influence, view, light condition, temperature, or interaction with the dynamic environment, both occurring inside and around the city, is geometrically traceable and is best understood and visualized in terms of its measurable direction and form.

The geometric organization of a given city is the first thing that is observed and remembered about it. Seeing it in a map, the layout of streets and blocks has recognizable shapes and gives other information as to what things look like from the ground. This provides visual information that helps dwellers navigate through the streets and districts. The geometric pattern of the frequency of intersections and the angles they make can reveal codes about divisions between districts and the uses within. They can also show system continuity and interruptions in it. By mapping and studying types of layouts and their morphology, cultural and historical insights can also be observed. Maps,

Figure 6: Three views of two major cores and the ray-fabric between them. Downtown and Oakland district in Pittsburgh.

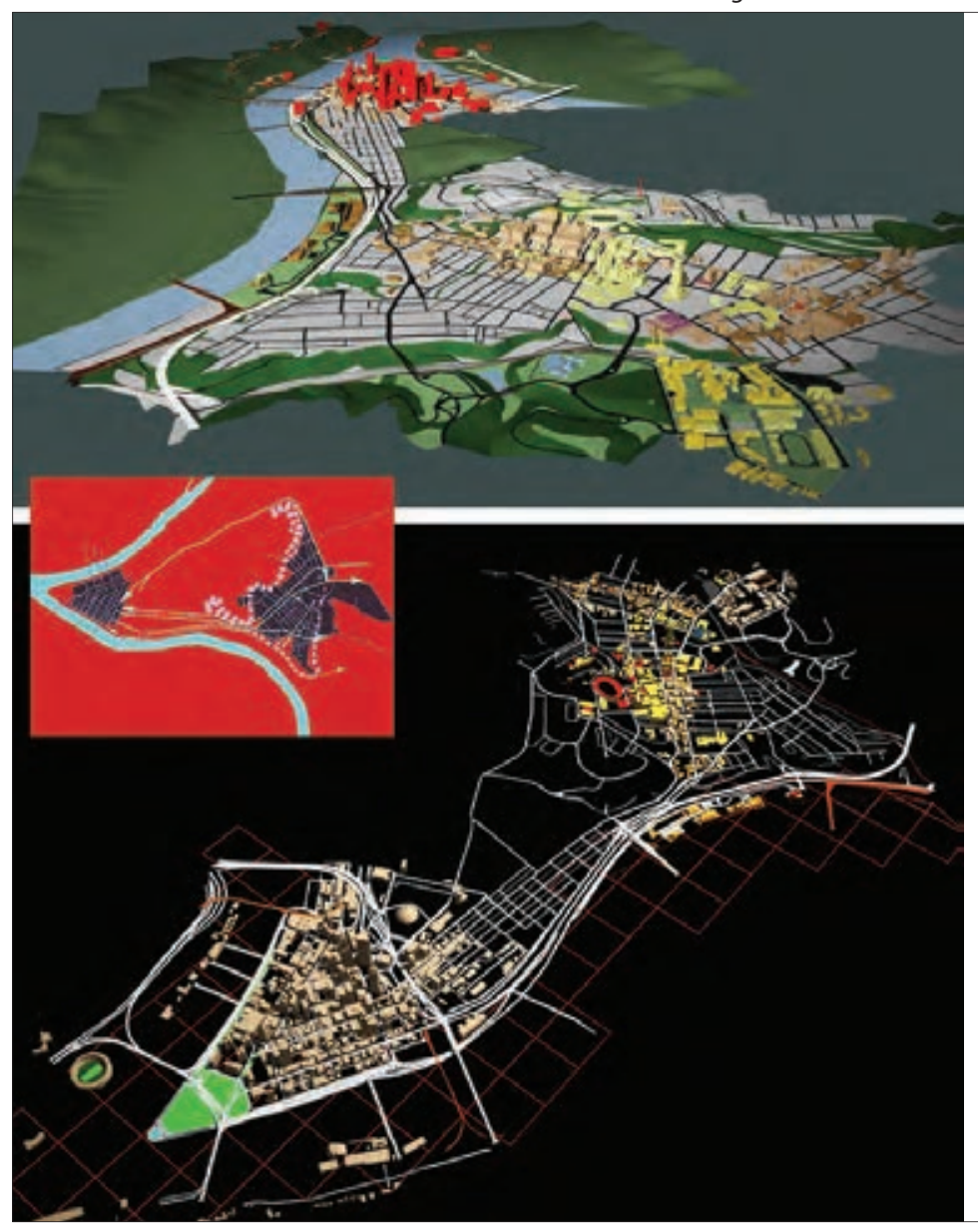


especially when augmented with satellite imagery, can further represent the larger geographic realm the city is built in, and can show points on the land of extended view, patterns of monumentality, areas of higher density, open spaces, places of intensified vegetation and bodies of water.

The collective layout of streets falls into geometric grid-types and varies from city to city, or sometimes between districts in a specific city. Frequently perturbations or deformations in these grids are caused by the shape of the land surface or even by less physical factors like ownership or land use that force the roads into a modified location (Figure 7). The whole grid overall can be bent at points by the process of correcting, adjusting, and realigning the component streets through longer distances. Different layout areas in the city will thus be broken into a series of spatial districts, or geometric realms, which will have distinct edges between themselves and adjacent realms. Sometimes the process is induced by major streets being built first, with adjustment to their route as they pass the front of a range of hills or along a coastline. The bending might also be applied to ease changes in grade. Other lesser streets are built perpendicular to them, to form orthogonal intersections. Where geometry differs in an adjacent area it may create an odd street between them with a bearing that bisects the angle between the two colliding realms. In other cases, for intentional reasons a change in layout geometry is employed for a district, such as places where the downtown grid is rotated against the rest of the city grid to reflect its significance (Gandelsonas, 1991).

As the city grows, construction of hierarchically larger systems will be required. The geometric logic of this next-scaled system, such as an expressway, may disrupt the continuity of original neighborhoods, and cut their grids into disconnected pieces as it passes through them. This can create fractured and damaged districts in the city, and isolated slashes of territory can become underutilized wastelands. These areas could also be well repurposed as natural areas, parks, and possibly even sites for intensively managed urban agriculture. They could also host forests and aquifer recharge areas and help provide continuity to surrounding natural systems.

The arrangement and scale of the land, structures, and spaces create a visual portion of the city called the viewshed. Arrayed in rooms and corridors along straight lines, these visual spaces and their points of view can extend well into the city's surrounding territory, and contribute significantly to the aesthetic and way-finding experience of the city (Figure 8). Cape Town, Rio de Janeiro, Los Angeles, Tehran, Denver, and many others have fairly dramatic distant landscapes in their greater viewshed. Others like Paris, Sydney, New York, Dubai, and Shanghai have intentionally built their own dramatic visual systems of monuments, parks, and skylines.

\section{Movement}

In a modern city, movement systems take up the largest part of the public realm. The geometry of this realm also creates the largest part of the city's order and capability for function. As the capability for efficient movement is expanded, the city will grow and the inhabitants will spend more time moving around in more parts of the larger city. As the city grows, hierarchical systems will need to be introduced, but as before, the logic of the layout of these superior systems may conflict with and locally disrupt the original order of the city even though overall they improve the efficiency of movement and can cause the city to grow at their ends.

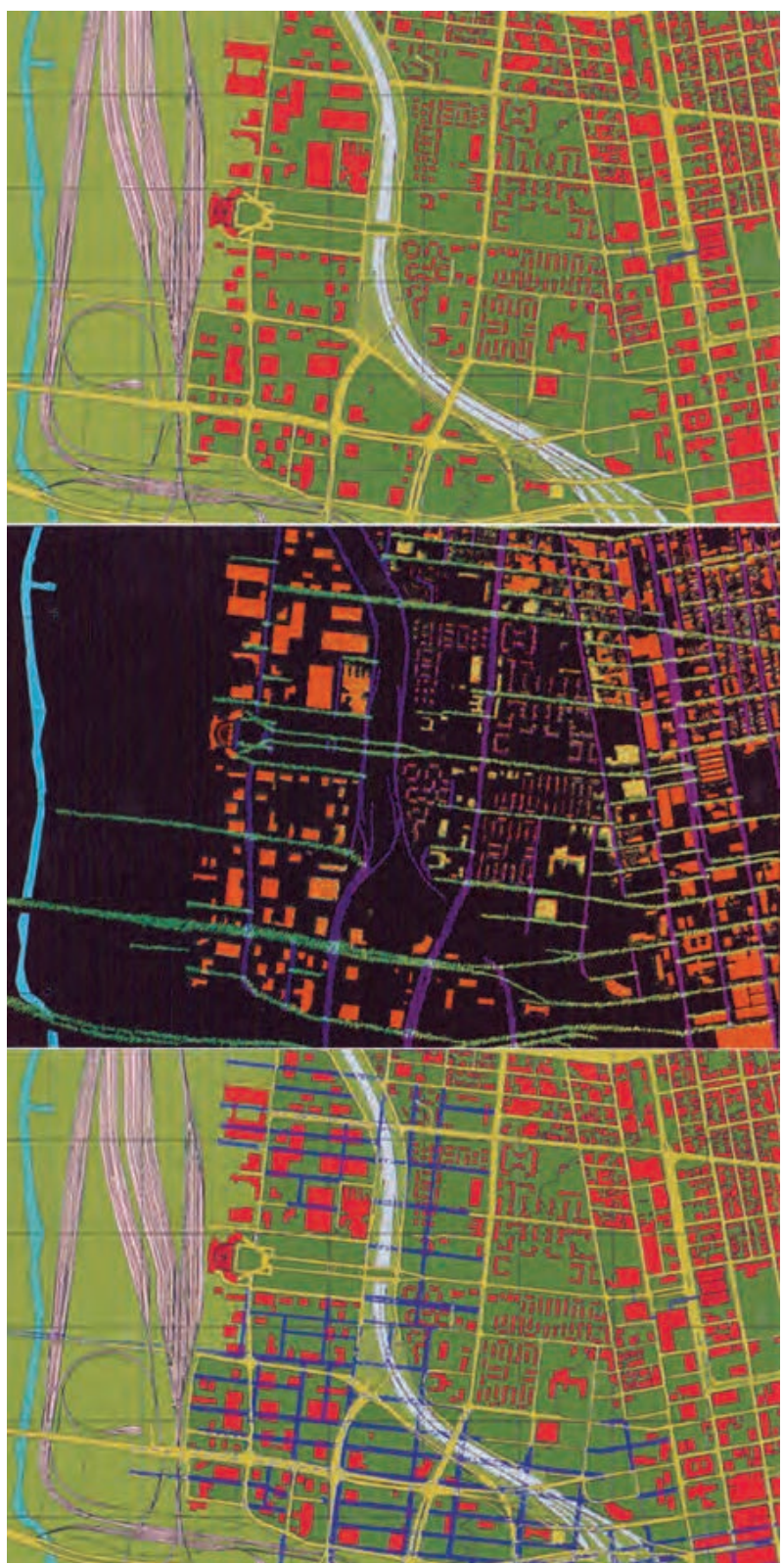

Figure 7: Three images that show disruptions to movement and build-out created by superior hierarchy movement systems, in this case 1-75 through the Queensgate district of Cincinnati. 


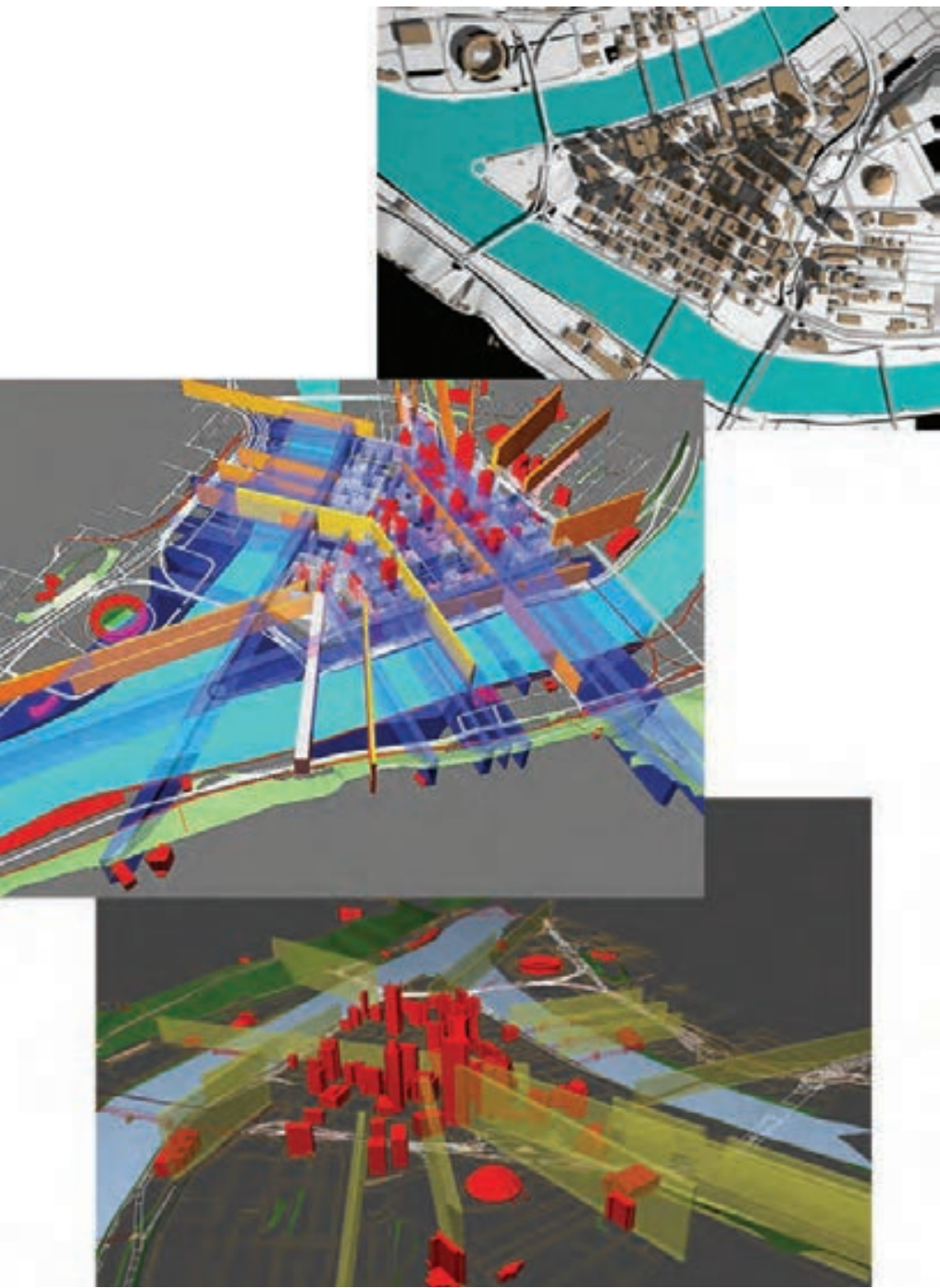

Figure 8: Three spatial/environmental phenomena observed in terms of their geometry. Top: shadow-fall in a high-rise district, Middle: View corridors into, and out, of a dense downtown. Bottom: Skyline monuments and the view corridors towards them, all in Pittsburgh.

Movement is the essence of a well-functioning city. The ideal is that every part of the city is connected directly to every other part of the city. Further in the ideal, systems of connection should be multimodal, continuously running, have many redundancies, and offer maximum freedom to their users.

The reality is that movement systems are very often undersized, incomplete, bottlenecked, and limited. At the same time, the growing city will accumulate stress and the demand for additional capacity will be added to the entire system. Every major new building or significant development creates a pattern of movement demand that goes from all of the included new floors, down the elevators to the lobbies, out into the streets, parking garages, sidewalks, mass transit routes, arteries, expressways; and then extends out to neighborhoods, transitoriented developments, individual apartments in apartment buildings, and individual houses (Figure 9). The whole system has to absorb the increased load. This set of impacts and the system that carries them is called the access tree (Regional Plan Association, 1969).

Development of a new, farther-out portion of a city is frequently triggered by construction, extension, or upgrade of a movement system, either existing or new. The development will occur all along the upgraded corridor but will tend to concentrate at the end of it, inducing latent demand for more extension of the system farther into unimproved surrounding territory. In a reverse way, extreme congestion will throttle development and can cause neglect or deterioration of large underserved or otherwise dysfunctional portions of the city.

The ideal less-disruptive super-hierarchical system is the one that is plane-isolated from the form-giving one on the surface, either above or below it. Subways accomplish this best of all. They can travel freely at various flat angles underneath surface arrangements and can change direction as required, and as a system they can be adjusted to functional optimums. Multiple layers can be built and interconnected, and they can

Figure 9: Visual elements from two views of moving along a street, isolated into component layers. Top to Bottom: Composite of layers, signs, building masses, overhead utilities, landscaping.

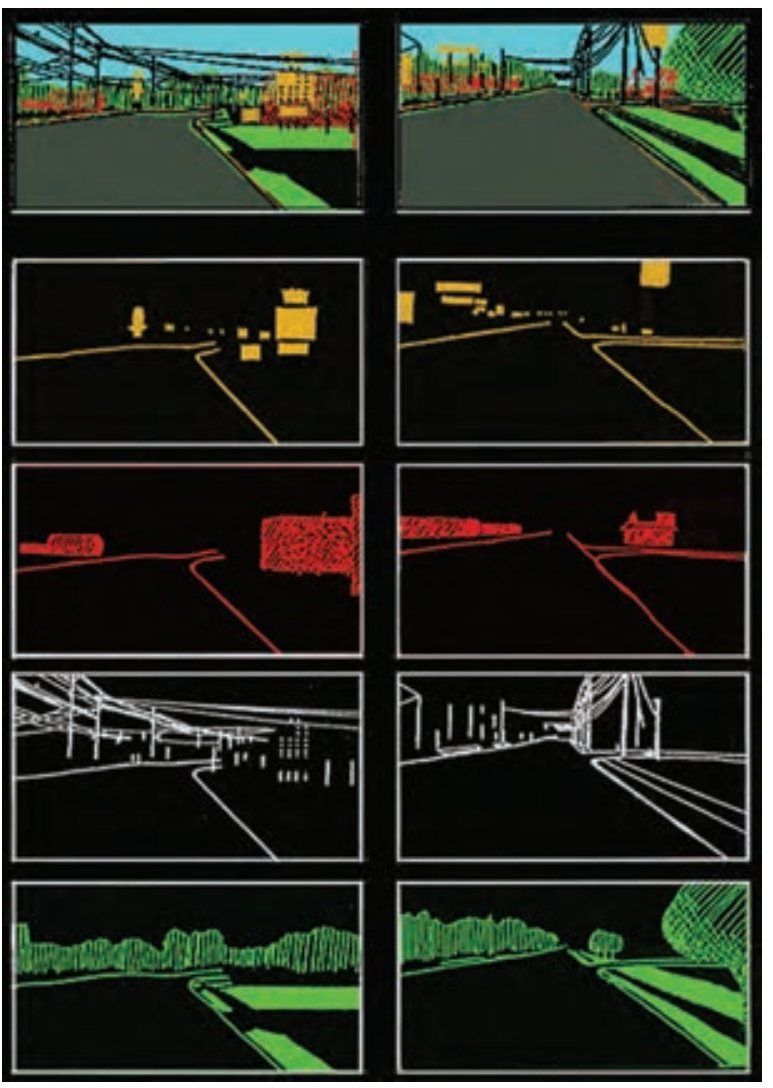


also be brought to the surface where needed to help level and maintain efficiency of their system of grades.

\section{Mass and Environment}

When singular urban structures such as industrial installations and districts of very tall buildings become large enough, they begin to interact with the dynamic environment at the lower range of geographical scales. A high-rise district in particular can create an interconnected system of tall-narrow vertical spaces that behave environmentally like narrow canyons, while the tallest parts of taller buildings rise above the general height of everything around them and have environmental qualities in common with mountaintops, such as susceptibility to high winds and lightning strikes (Figure 10).

Urban structures and their spaces generally create a desertlike environment with extended areas of rock-like pavement, walls and roofs. This, in turn creates, a hydrological and thermo-dynamic environment that is desert-similar. Lightcolored surfaces create high albedo, or reflection of sunlight; even darker surfaces that may absorb more sunlight give it up quickly as radiant heat, and resultant temperature changes are often extreme. Generally the temperature in and around the entire city can be expected to be somewhat higher than the surrounding areas. This is termed the urban heat island.

The surface hydrology occurring around and through the city is its watershed or drainage net, and every exposed surface of the city must be engineered to shed water logically into this network. Extended areas of impermeable pavement can cause extreme, sudden, hazardous sheet drainage, and contribute overall to larger regional run-off and floods. Properly designed urban surfaces will absorb more water, and have landscaped breaks and undulating surfaces to help break up and slow down sheet flows.

The immediate piece of the atmosphere around the city is called its airshed. Normally this air acts as the ventilation system of the city, but in cases where the surrounding landforms form a bowl-shaped basin around it, the airflows can stagnate and accumulate impurities and complex pollutants around the city. If large urban structures or potential pollution sources are badly located on the land, they can sometimes exaggerate and worsen these effects; likewise if the city is located at high elevation, or in a solar-intensive region, the pollutants' chemistry can be photo-chemically changed and made more complex, creating a smog of worse pollutants. With proper consideration and clear understanding of these phenomena, things can be placed more appropriately in the air-shed and negative impacts may be diminished, although reducing emissions overall is the best approach.

Microclimates are created around individual objects and by groups of objects, depending on a combination of factors like the depth and intensities of permanent shadow, or constant wind or solar exposure. Understanding microclimates and

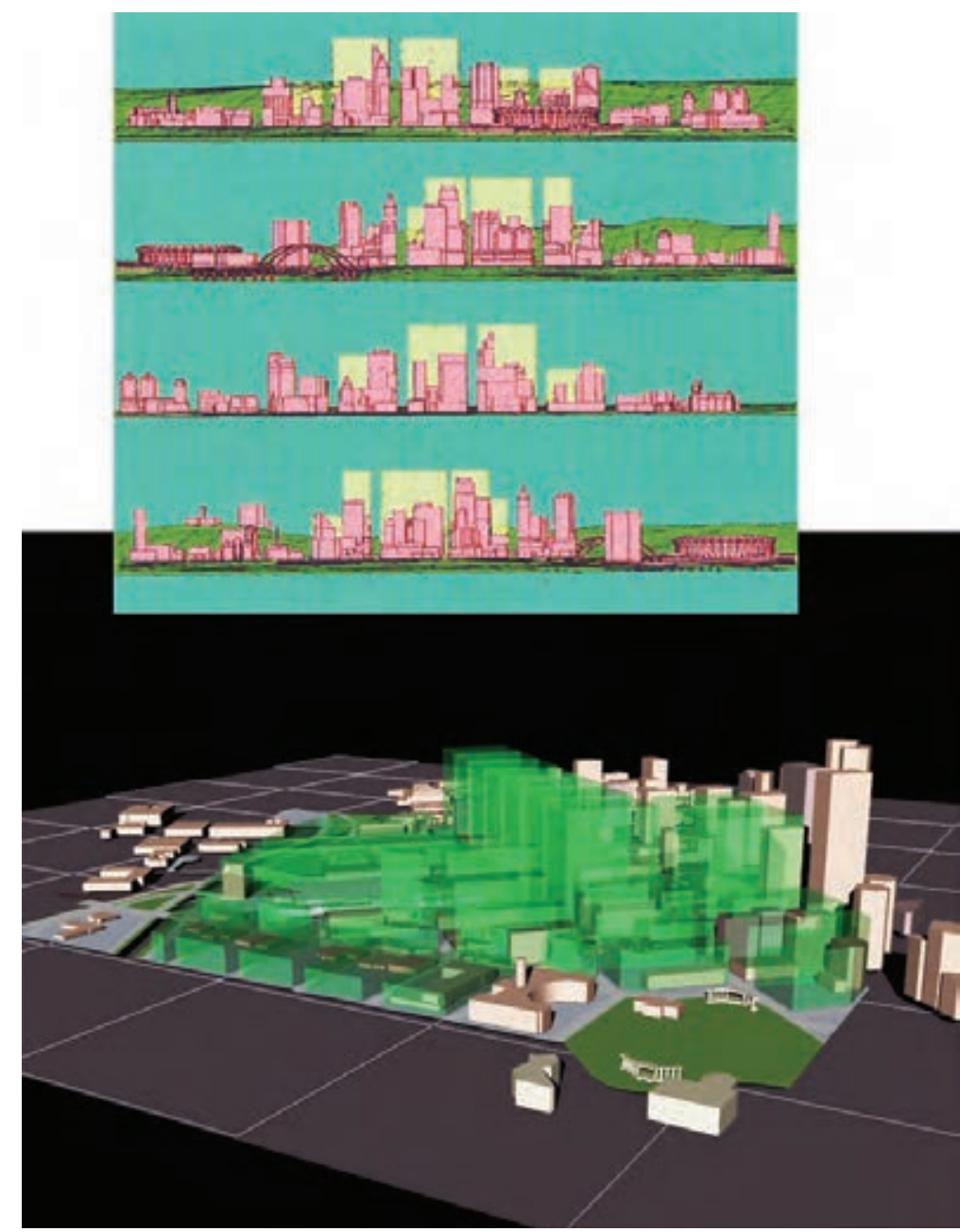

Figure 10: Two studies of skylines. Above: directional views of the elevation of downtown Cincinnati including height-limit volumes and surrounding landforms. Below: Volumetric model of tallest buildings in Denver with the adjacent height-limit volumes (green).

how building orientation and arrangement creates them can give designers a mechanism to create more outside comfort for urban residents, and even modify an otherwise harsher general climate. Ignoring these factors can create wind tunnels and other environmental hazards. Introduction of plant materials into and on every possible surface of a city can greatly modify negative environmental factors by buffering heat-island effects and working to filter and purify the urban atmosphere (Marsh, 1983).

\section{Synthesis}

What this essay is calling for is a literal revolution in city design, one that can enable and can deliver the kind of response required by cities to meet, and survive, the monumental challenges posed by the effects of climate change; and at the same time create renewed or relocated cities that produce a 
radically diminished contribution to the factors that cause climate change.

We have proved at various historical points that combined human effort can accomplish fairly significant and durable things. With progress it may become possible that any condition or contingency could be designed for. Anything that can be done at any level can be optimized and improved to the next one, with sufficient collaborative commitment. Given enough observation and analysis, we can devise and apply systems of preparation for our cities. Many types of event impacts could be minimized to a point that they have sufficiently less effect on the life of the city, thus allowing the city to survive.

In order to be capable of designing and then executing the modifications that cities need, a change of base is required: a new way of looking at cities and of understanding them. This also requires an acceptance of an expanded sense of what is possible and a willingness to confront what isn't. If we rise to this challenge as a species, the outcome could take us well beyond mere survival to a next and more advanced phase in our development.

Figure 11: A successively decomposed view of the volumetric model of a high-rise part of Cincinnati. From the top-composite model it proceeds down to the bottom streetscape layer.

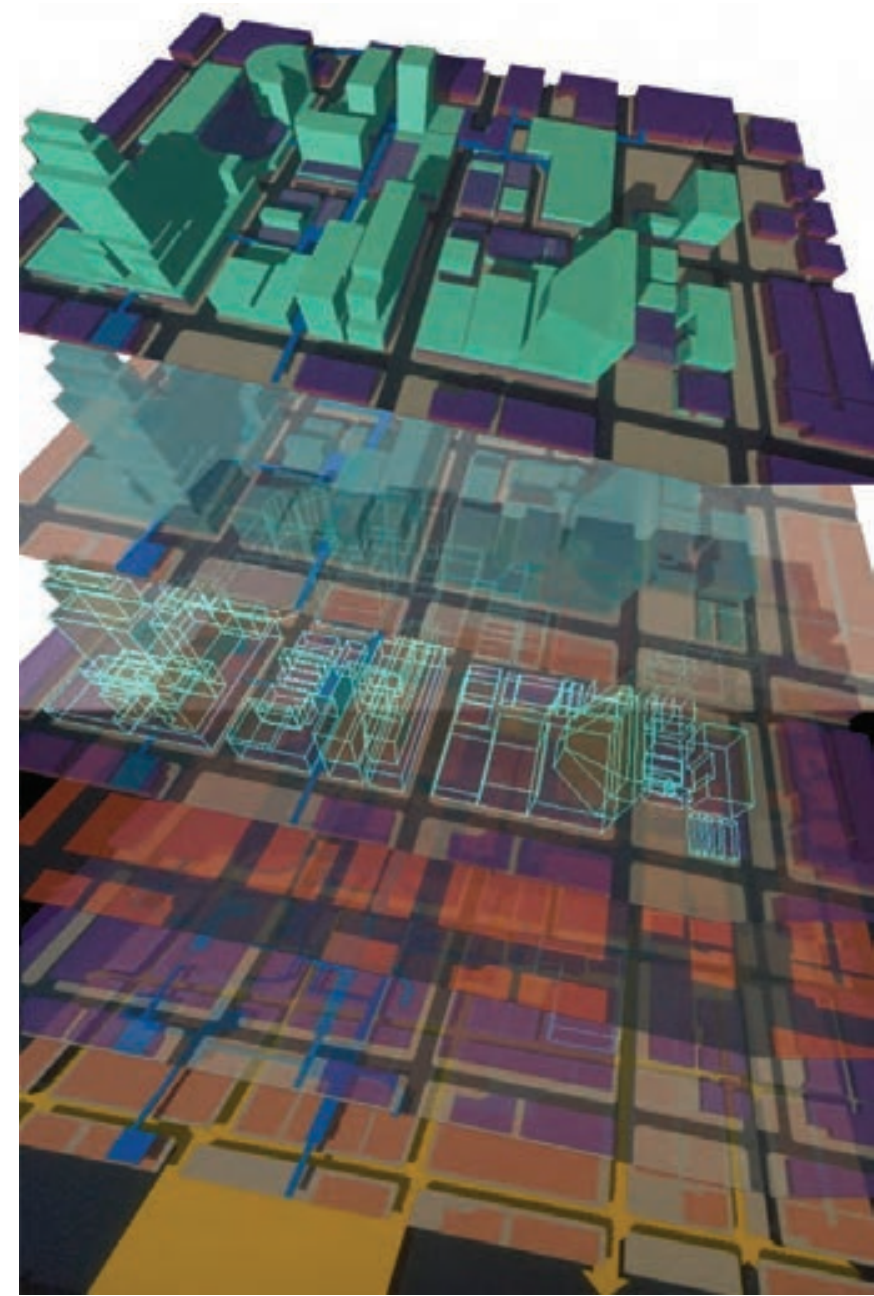

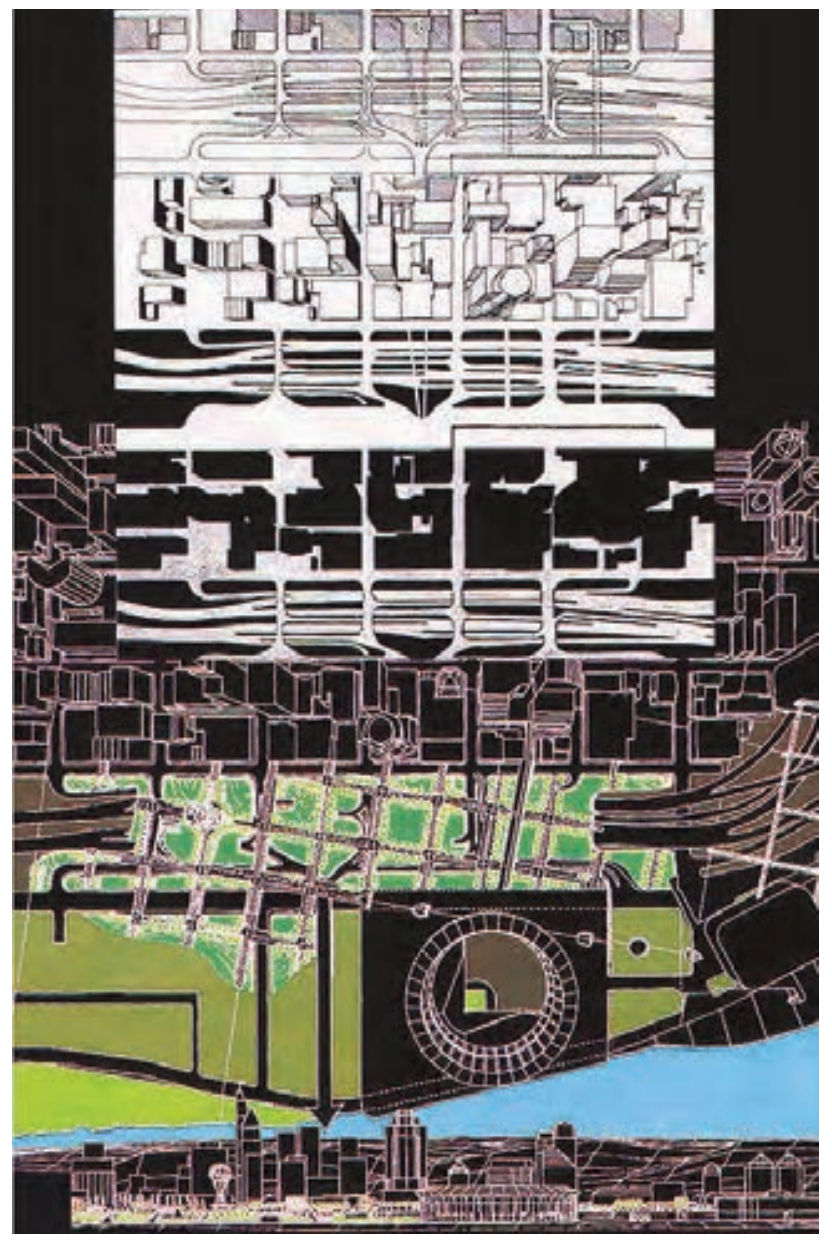

Figure 12: A series of analytical images leading down towards a design solution. In this case, a proposal for an air-rights park over a downtown expressway in front of Cincinnati.

What kind of urban future is possible? Completely computerized intelligent-cities, robotic cities, cities with moveable components, waste-free economies, equitable and open societies, beautiful, natural cities, and cities powered by unlimited clean energy.

All of these things might be possible if we collectively push hard enough. They just need to be designed, tested, and installed; this only requires that we embrace urban design wholesale, as an art and a science, distinct from but part of all the other disciplines.

What we need to do is make up enough of our minds, allocate the required resources, and do it. 


\section{References}

Appleyard, Donald; Lynch, Kevin; and Myer, John. 1971. The View from the Road. Cambridge, MA: M.I.T. Press.

Bacon, Edmund. 1967. Design of Cities. New York: Viking Press.

Branch, Melville. 1988. Comprehensive City Planning. Washington, D.C.: A.P.A. Press,.

Gandelsonas, Mario. 1991. The Urban Text. Cambridge, MA: M.I.T. Press.

Gosling, David. 2003. The Evolution of American Urban Design, West Sussex, England: Wiley Academy.

Gosling, David and Maitland, Barry. 1991. Concepts of Urban Design. Cambridge, MA: Academy Editions/ St. Martin's Press.

Harvey, David. 1985. Consciousness and the Urban Experience, Baltimore, MD; John Hopkins University Press.

Hedman, Richard and Jazewski, Andrew. 1984. Fundamentals of Urban Design. Washington DC: A.P.A. Press.

Lynch, Kevin. 1960. The Image of the City. Cambridge, MA: M.I.T. Press.

McHarg, lan. 1969. Design with Nature. Garden City, NY: Natural History Press.

Marsh, William. 1983. Landscape and Planning, Environmental Applications. New York: John Wiley \& Sons.

Mitchell, William. 1997. City of Bits. Cambridge, MA: M.IT. Press. Norberg-Schultz, Christian. 1980. Genius Loci. New York: Rizzoli.

Regional Plan Association. 1969. Urban Design Manhattan. New York: A Studio Book.

Rossi, Aldo. 1984. The Architecture of the City. Cambridge, MA: M.I.T. Press.

Trancik, Roger. 1986. Finding Lost Space - Theories of Urban Design. New York: Van Nostrand Reinhold.

Tschumi, Bernard. 1994. Event-Cities. Cambridge, MA: M.I.T. Press. 